The original publication is available at

http://dx.doi.org/10.1016/j.theochem.2008.10.016

Print version: Journal of Molecular Structure: THEOCHEM 895 (2009) 26-29

\title{
Stability and Structure of 5-Tellurouracil Cations
}

\author{
E. A. Kümmerle *, E. Pomplun \\ Geschäftsbereich Sicherheit und Strahlenschutz, Forschungszentrum Jülich, 52425 Jülich, Germany
}

\begin{abstract}
In the context of a conceivable Coulomb explosion within the DNA strand after the decay of DNA-incorporated ${ }^{125} \mathrm{I}$ or ${ }^{123} \mathrm{I}$, the stability and structure of 5 -tellurouracil cations and the dissociated states $\mathrm{C}_{4} \mathrm{H}_{3} \mathrm{~N}_{2} \mathrm{O}_{2}^{m-n}+\mathrm{Te}^{n}$ were investigated by density functional theory calculations for total charges between 0 and +7 . Three isomeric structures of 5 -tellurouracil with different $\mathrm{Te}$ atom positions were identified, depending on the cation charge. 5-tellurouracil is (meta-)stable up to the charge +5 . Thymine, telluromethane and telluroethane cations were examined for comparison.
\end{abstract}

Keywords: Density functional calculations, Coulomb explosion, DNA-incorporated Auger electron emitter, Iodouracil, Thymine

\section{Introduction}

DNA-incorporated ${ }^{125} \mathrm{I}$ and ${ }^{123} \mathrm{I}$ in the form of 5 iodouracil or iododeoxyuridine $\left({ }^{123 / 125} \mathrm{IUdR}\right)$ have been demonstrated to cause a strong radiotoxic effect comparable to high-LET radiation, e.g. [1-3]. A number of theoretical studies have identified the shower of low-energy Auger electrons emitted during the decay to ${ }^{125} \mathrm{Te}$ or ${ }^{123} \mathrm{Te}$, respectively, as being responsible for this effect e.g. [4-6]. However, it is still questionable whether the severe impact of closely localised energy deposition by these shortranging electrons is the only mechanism leading to molecular DNA strand damage. The extremely fast emission of many electrons during the Auger cascade leaves a highly ionised atom behind. Since this atom is part of a molecule, reorganisational consequences for this molecule must be expected. Such a process - a so-called Coulomb explosion - was discussed some time ago by Carlson and White [7] on the basis of experiments with iodomethane and iodoethane.

In contrast to the many studies on the Auger electron action mode, there are very few investigations on the possibility and relevance of a Coulomb explosion [8-10]. From their experimental data, Martin and Lobachevski [8] concluded that about one half of the DNA single strand breaks

\footnotetext{
* Corresponding author.

E-mail addresses: E.Kuemmerle@fz-juelich.de (E.A. Kümmerle), E.Pomplun@fz-juelich.de (E. Pomplun)
}

induced by the decay of ${ }^{125} \mathrm{I}$ are associated with the consequences of positive charges on the daughter atom. In the two theoretical studies, semiempirical quantum mechanical computer programs were used to identify stable molecular configurations of ${ }^{123 / 125}$ IUdR after increasing the number of charges. No stable molecule was found with a total charge of $\geq+5 \mathrm{e}$. In addition, molecular dynamics simulations applied to consider conformational changes as a function of time showed that the breaking of chemical bonds took place between the atoms with the steepest charge increase.

In this work, the stability and structure of 5tellurouracil cations were investigated as a function of increasing charge by means of the fully quantum mechanical approach of density functional theory (DFT). Additionally, thymine, telluromethane and telluroethane cations were examined for comparison.

\section{Method}

The geometries of various isomers and transition states for cations of 5-tellurouracil, thymine, telluromethane and telluroethane were optimised at the B3LYP level of the density functional theory using the Gaussian 03 software [11]. The basis set Lanl2DZ was applied for Te and 6-31G(d,p) for the other atoms. For Te, Lanl2DZ was also used as an effective core potential. Additionally, the vibra- 
tional frequencies and eigenvectors were calculated at the same level to distinguish between a transition state, i.e. a saddle point in the potential energy surface (PES) involving an imaginary vibrational frequency, and a (meta-)stable state, i.e. a (local) minimum in the PES which implies only real vibrational frequencies.

\section{Results and discussion}

\section{$3.1 \quad 5$-Tellurouracil}

For the cations of 5-tellurouracil, three isomers were found that differed with regard to the bonding of Te to the uracil molecule. Te may be bound to the $\mathrm{C}(5)$ atom, to $\mathrm{C}(5), \mathrm{C}(4)$ and $\mathrm{O}(4)$ simultaneously or solely to $\mathrm{O}(4)$ (which should be designated 4-tellurouracil), see Fig. 1. These isomers are denoted as $\mathrm{Te}-\mathrm{C}$, $\mathrm{Te}-(\mathrm{C}, \mathrm{O})$ and $\mathrm{Te}-\mathrm{O}$ isomers in the following. The stability of these isomers depends on the charge of the molecule, see Table 1 and Fig. 3. The neutral molecule has only one isomer, the $\mathrm{Te}-\mathrm{C}$ isomer. In the case of the singly charged cation, the $\mathrm{Te}-(\mathrm{C}, \mathrm{O})$ isomer is stable and the $\mathrm{Te}-\mathrm{C}$ isomer is metastable. The same holds for the doubly charged cation, but additionally a metastable $\mathrm{Te}-\mathrm{O}$ isomer also exists. For the more highly charged cations, the $\mathrm{Te}-\mathrm{C}$ isomer no longer exists and from the charge +4 onwards, the $\mathrm{Te}-\mathrm{O}$ isomer is the most stable one. With the charge +6 , the molecule dissociates into the 5 monodehydrouracil cation $\mathrm{C}_{4} \mathrm{H}_{3} \mathrm{~N}_{2} \mathrm{O}_{2}^{3+}$ and $\mathrm{Te}^{3+}$. There are two isomers of 5-monodehydrouracil (denoted as MDU in the following), a hexagonal and a pentagonal one with a $-\mathrm{C}-\mathrm{O}$ group, see Fig. 2 . Table 1 and Fig. 3 also show the binding energies for the dissociated cations MDU + Te considering both MDU isomers. The pentagonal MDU isomer is more stable than the hexagonal one for all charge levels. The hexagonal MDU isomer with the charge +1 is not stable, it is a transition state whose instable vibration vector is orthogonal to the symmetry plane. The pentagonal MDU + Te cations are energetically advantageous compared to the tellurouracil cation for total charges as small as +2 . The DFT calculations showed that for even total charges, the charge is distributed equally between Te and MDU, and for odd charges, MDU is more highly charged by one. The cyclic structure of the MDU cation breaks at a charge of +5 , see Fig. 2 .

The structures and binding energies could not be determined for all transitions occurring due to convergence difficulties. The ascertained transition states between the $\mathrm{Te}-(\mathrm{C}, \mathrm{O})$ and $\mathrm{Te}-\mathrm{O}$ isomers as well as between the $\mathrm{Te}-\mathrm{O}$ isomers and the MDU cations show that the energy barriers for the dissociation are very low for the total charges +4 and +5 .

Table 2 shows parameters of the Te bond in the different isomers of 5-tellurouracil. The $\mathrm{Te}-\mathrm{C}(5)$ bond distance for the $\mathrm{Te}-\mathrm{C}$ isomer does not vary much with the molecular charge. For the $\mathrm{Te}-(\mathrm{C}, \mathrm{O})$ isomer, the bond distances $\mathrm{Te}-\mathrm{C}(5)$ and $\mathrm{Te}-\mathrm{O}(4)$ vary unsteadily. While the bond distance $\mathrm{Te}-\mathrm{O}(4)$ again varies unsteadily for the $\mathrm{Te}-\mathrm{O}$ isomer, the angle $\mathrm{Te}-\mathrm{O}(4)-\mathrm{C}(4)$ continuously grows.

\subsection{Thymine}

In contrast to the tellurium atom, the methyl group does not tend to move to the neighbouring oxygen atom with increasing molecular charge. With the charge +5 , the molecule pushes one of protons out of the methyl group, i.e. it dissociates into the 7monodehydrothymine (MDT) cation $\mathrm{C}_{5} \mathrm{H}_{5} \mathrm{~N}_{2} \mathrm{O}_{2}^{4+}$ and $\mathrm{H}^{+}$. As shown in Table 3, the $\mathrm{MDT}^{m-1}$ cation is energetically advantageous compared to the thymine cation for charges $m \geq+3$. The MDT $^{m-1}$ cation breaks at a charge of $m-1=+7$. Evidently, MDT is slightly more resistant to the Coulomb explosion than MDU because the charge can be distributed over a larger volume.

\subsection{Telluromethane and telluroethane}

Telluromethane and telluroethane both exist up to the charge +3 . However, in the case of telluroethane, the position of the $\mathrm{Te}$ atom changes such that it forms an acute-angled triangle beginning at a charge of +1 . With increasing charge, the triangle becomes nearly isosceles, see Table 4 . The $\mathrm{Te}-\mathrm{C}$ bond distance in telluromethane decreases with increasing charge (Table 4). The dissociated states $\mathrm{C}_{2} \mathrm{H}_{5}^{m-n}+\mathrm{Te}^{n}$ and $\mathrm{CH}_{3}^{m-n}+\mathrm{Te}^{n}$ (with $n=m / 2$ for even $m, n=(m+1) / 2$ for odd $m$ in both cases) are energetically advantageous beginning with the charge $m=+2$ for telluromethane as well as for telluroethane, see Table 5. The dissociation energy barrier for telluroethane is slightly lower than for telluromethane for the charges +2 and +3 (see transition states in Table 5 ), the path of the Te ion via the position next to the $\mathrm{C}-\mathrm{C}$ bond seems to be an easy passage.

The comparison with tellurouracil shows that the tellurouracil molecule can bear about twice as 

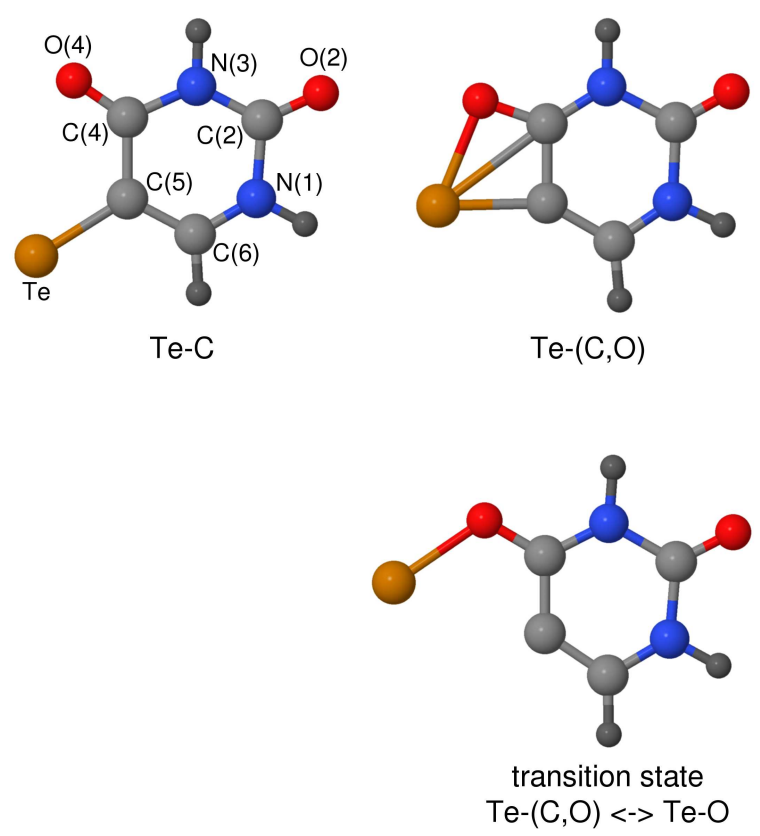
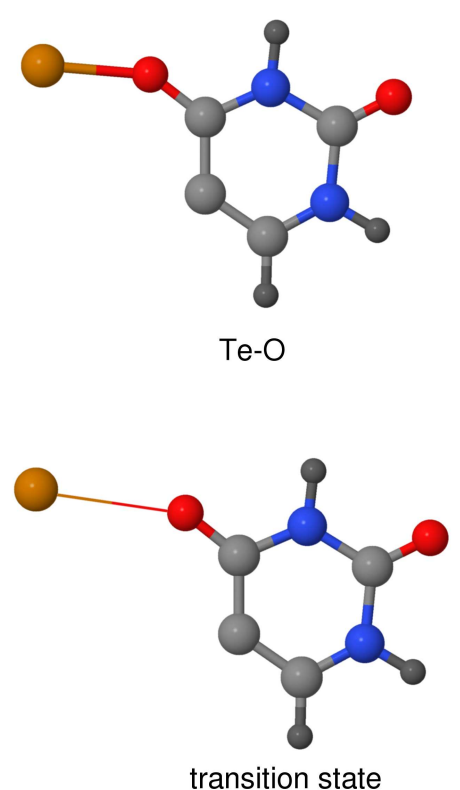

Te-O $<->$ hex. MDU + Te

Figure 1: Isomer and transition state structures of 5-tellurouracil cations.

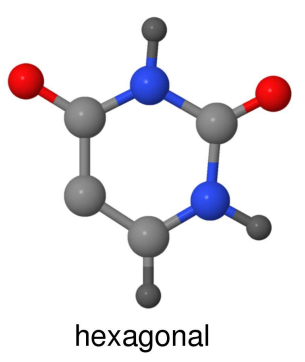

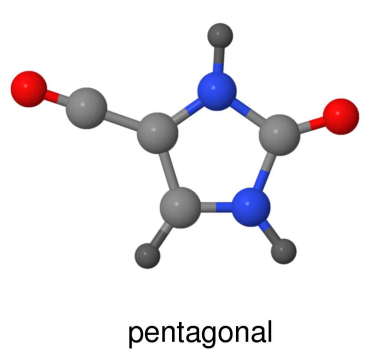

pentagonal

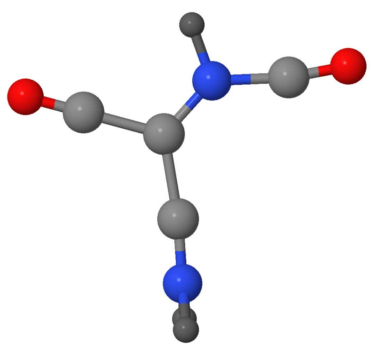

broken

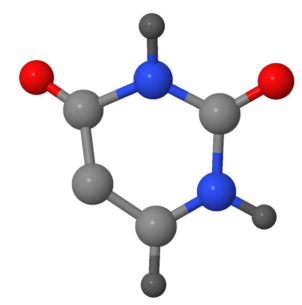

transition state

hex. <-> pent.

(non-planar)

Figure 2: Isomer structures of 5-monodehydrouracil (MDU) cations.

many charges as telluromethane or telluroethane, which is obviously due to the fact that the charge is extended over a larger volume in the case of the tellurouracil molecule. Nevertheless, because the average charge on $\mathrm{Te}$ of +15 at the end of the Auger cascade following a ${ }^{125} \mathrm{I}$ decay is more than twice as high as that required to cause the dissociation of tellurouracil, it can be expected that tellurouracil will fragment in a similar manner to that observed experimentally for telluromethane and telluroethane by Carlson and White [7].

\subsection{Prospects}

Further investigations may aim at the charge capacity of larger units such as tellurodeoxyuridine or whole segments of a DNA strand. In that context, another question will become crucial: How fast will a high positive excess charge be spread over a large molecule? The Auger cascade of the ${ }^{125} \mathrm{I}$ decay will produce an average charge of +7 within $10^{-16}$ to $10^{-14} \mathrm{~s}$ and a charge of +15 within $10^{-9} \mathrm{~s}$ on the Te atom. The time constants found for different charge transfer processes in DNA vary over an ex- 
Table 1: Energies [hartree] for 5-tellurouracil, for the dissociated molecule $\mathrm{MDU}^{m-n}+\mathrm{Te}^{n}$ and for transition states (ts) with total charges $m$ between 0 and $+7(n=m / 2$ for even $m, n=(m-1) / 2$ for odd $m$ ). The hexagonal MDU isomer with $m-n=+1$ (i.e. $m=+1$ and $m=+2$ ) is a transition state.

\begin{tabular}{|c|c|c|c|c|c|c|c|c|}
\hline & $m:$ & +1 & +2 & +3 & +4 & +5 & +6 & +7 \\
\hline$\overline{\mathrm{Te}-\mathrm{C}}$ & -422.243 & -421.946 & -421.464 & - & - & - & - & - \\
\hline ts & - & - & - & - & - & - & - & - \\
\hline $\mathrm{Te}-(\mathrm{C}, \mathrm{O})$ & - & -421.954 & -421.479 & -420.789 & -419.867 & -418.745 & - & - \\
\hline ts & - & - & - & -420.754 & -419.860 & -418.741 & - & - \\
\hline $\mathrm{Te}-\mathrm{O}$ & - & - & -421.406 & -420.764 & -419.891 & -418.829 & - & - \\
\hline ts & - & - & -421.360 & -420.733 & -419.878 & -418.817 & - & - \\
\hline hex. MDU + Te & -422.083 & -421.724 & -421.381 & -420.838 & -420.143 & -419.373 & -418.401 & -417.363 \\
\hline ts & - & - & - & -420.827 & -420.132 & - & - & - \\
\hline pent. MDU $+\mathrm{Te}$ & -422.096 & -421.854 & -421.510 & -420.993 & -420.298 & -419.543 & -418.571 & -417.541 \\
\hline
\end{tabular}

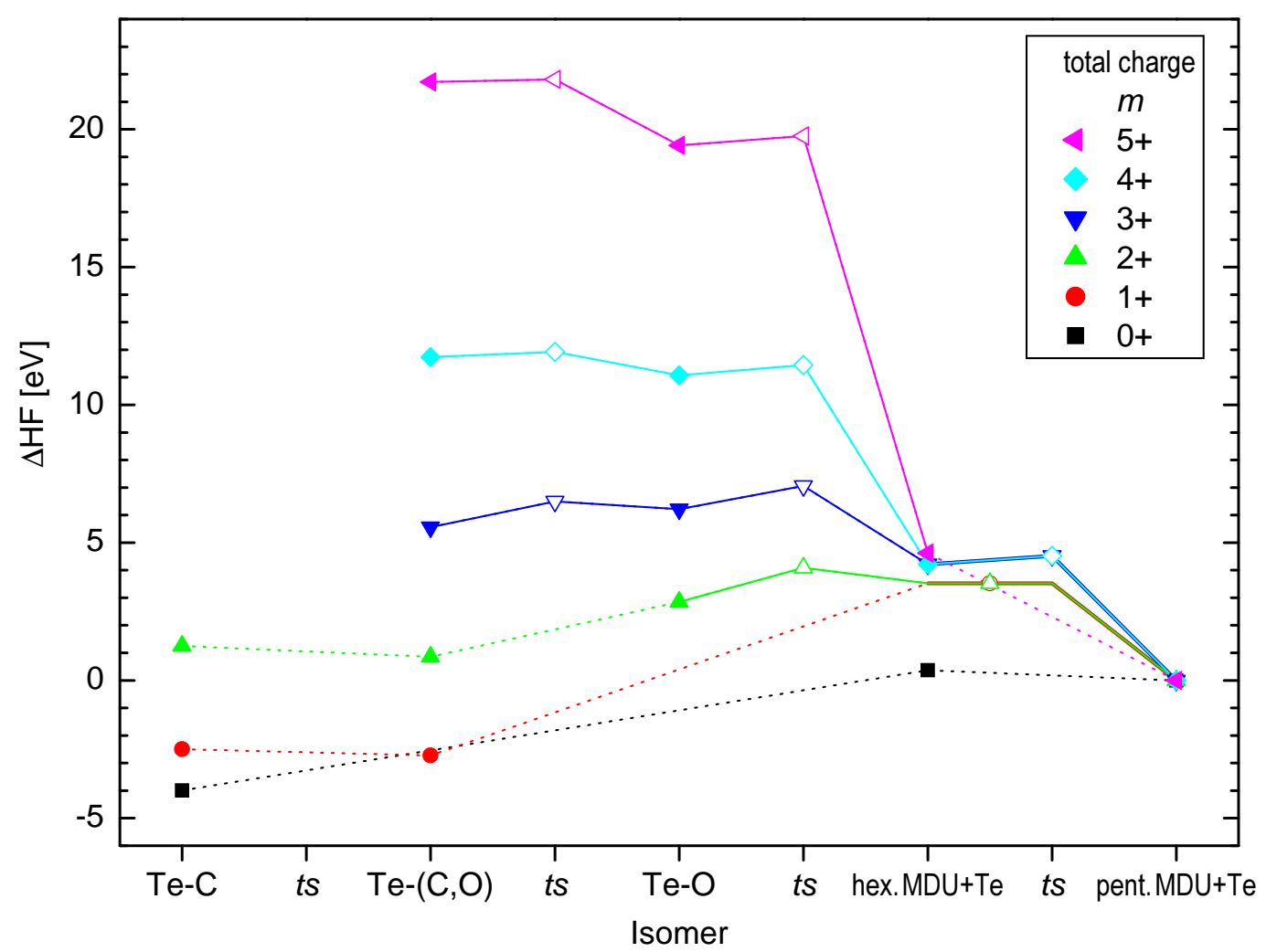

Figure 3: Differential energy relative to the energy of the dissociated molecule $\mathrm{MDU}^{m-n}+\mathrm{Te}^{n}$ with pentagonal MDU structure $(n=m / 2$ for even $m, n=(m-1) / 2$ for odd $m)$. Closed symbols: (meta)stable states, open symbols: transition states. Dotted lines: transition states are missing. The hexagonal MDU isomer with $n=+1$ (i.e. $m=+1$ and $m=+2$ ) is a transition state.

tremely wide scale, from less than 1 femtosecond to several tenths of a second $[12,13]$.

\section{References}

[1] K.G. Hofer, W.L. Hughes, Rad. Res. 47 (1971) 94.

[2] L.E. Feinendegen, H.H. Ertl, V.P. Bond, in: H. Ebert (Ed.), Proc Symposium on Biophysical
Aspects of Radiation Quality, IAEA, Vienna (1971) 419.

[3] G.M. Makrigiorgos, A.I. Kassis, J. Baranowska-Kortylewicz, K.D. McElvany, M.J. Welch, K.S.R. Sastry, S.J. Adelstein, Rad. Res. 118 (1989) 532.

[4] E. Pomplun, M. Terrissol, E. Kümmerle, Rad. Prot. Dosim. 122 (2006) 80. 
Table 2: Bond distances $[\AA]$ and angles $\left[{ }^{\circ}\right]$ for the bonding of Te in 5-tellurouracil with charges $m$ between 0 and +5 .

\begin{tabular}{|c|c|c|c|c|c|c|c|}
\hline \multirow[b]{2}{*}{ Isomer } & $m$ & 0 & +1 & +2 & +3 & +4 & +5 \\
\hline & \multicolumn{7}{|l|}{ Bond parameter } \\
\hline$\overline{\mathrm{Te}}-\mathrm{C}$ & $\mathrm{Te}-\mathrm{C}(5)$ & 2.089 & 1.997 & 2.028 & - & - & - \\
\hline \multirow[t]{3}{*}{$\mathrm{Te}-(\mathrm{C}, \mathrm{O})$} & $\mathrm{Te}-\mathrm{C}(5)$ & - & 2.133 & 2.076 & 2.024 & 2.240 & 2.604 \\
\hline & $\mathrm{Te}-\mathrm{C}(4)$ & - & 2.561 & 2.531 & 2.531 & 2.633 & 2.760 \\
\hline & $\mathrm{Te}-\mathrm{O}(4)$ & - & 2.132 & 2.097 & 2.102 & 2.059 & 1.969 \\
\hline \multirow[t]{2}{*}{$\mathrm{Te}-\mathrm{O}$} & $\mathrm{Te}-\mathrm{O}(4)$ & - & - & 1.974 & 2.015 & 2.183 & 1.971 \\
\hline & $\mathrm{Te}-\mathrm{O}(4)-\mathrm{C}(4)$ & - & - & 131.6 & 147.0 & 157.8 & 173.3 \\
\hline
\end{tabular}

Table 3: Energies [hartree] for thymine and for the dissociated molecule $\mathrm{MDT}^{m-1}+\mathrm{H}^{+}$with total charges $m$ between 0 and +7 .

\begin{tabular}{|c|c|c|c|c|c|c|c|c|}
\hline & $m:$ & +1 & +2 & +3 & +4 & +5 & +6 & +7 \\
\hline $\mathrm{hy}$ & -454.149 & 453.837 & -453.298 & -452.548 & -451.615 & - & - & - \\
\hline$+\mathrm{H}^{+}$ & - & - & -453.243 & -452.690 & -451.948 & -450.946 & -449.740 & -448.407 \\
\hline
\end{tabular}

Table 4: Bond distances $[\AA]$ for the bonding of Te in telluromethane and telluroethane with charges $m$ between 0 and +3 .

\begin{tabular}{|c|c|c|c|c|c|}
\hline & Bond parameter & 0 & +1 & +2 & +3 \\
\hline \multirow[t]{2}{*}{ Telluroethane } & $\mathrm{Te}-\mathrm{C}(1)$ & 2.197 & 2.157 & 2.190 & 2.241 \\
\hline & $\mathrm{Te}-\mathrm{C}(2)$ & 3.160 & 2.449 & 2.442 & 2.355 \\
\hline Telluromethane & $\mathrm{Te}-\mathrm{C}$ & 2.179 & 2.107 & 2.044 & 1.951 \\
\hline
\end{tabular}

Table 5: Energies [hartree] for telluromethane, telluroethane, for the dissociated molecules $\mathrm{C}_{2} \mathrm{H}_{5}^{m-n}+$ $\mathrm{Te}^{n}$ and $\mathrm{CH}_{3}^{m-n}+\mathrm{Te}^{n}$ (with $n=m / 2$ for even $m, n=(m+1) / 2$ for odd $m$ ) and for dissociation transition states.

\begin{tabular}{|c|c|c|c|c|}
\hline & $m:$ & +1 & +2 & +3 \\
\hline$\overline{\mathrm{CH}_{3} \mathrm{Te}}$ & -47.941 & -47.589 & -47.014 & -46.128 \\
\hline ts & - & - & -46.986 & -46.099 \\
\hline $\mathrm{CH}_{3}^{m-n}+\mathrm{Te}^{n}$ & -47.807 & -47.463 & -47.105 & -46.411 \\
\hline$\overline{\mathrm{C}_{2} \mathrm{H}_{5} \mathrm{Te}}$ & -87.257 & -86.925 & -86.385 & -85.552 \\
\hline ts & - & - & -86.370 & -85.540 \\
\hline $\mathrm{C}_{2} \mathrm{H}_{5}^{m-n}+\mathrm{Te}^{n}$ & -87.129 & -86.785 & -86.489 & -85.794 \\
\hline
\end{tabular}

[5] S. Edel, M. Terrissol, A. Peudon, E. Kümmerle, E. Pomplun, Rad. Prot. Dosim. 122 (2006) 136.

[6] M. Terrissol, S. Edel, E. Pomplun, Int. J. Rad. Biol. 80 (2004) 905.

[7] T.A. Carlson, R.M. White, J. Chem. Phys. 38 (1963) 2930.

[8] P.N. Lobachevsky, R.F. Martin, Rad. Res. 153 (2000) 271.

[9] E. Pomplun, Acta Oncologica 39 (2000) 673.
[10] E. Pomplun, G. Sutmann, Int. J. Rad. Biol. 80 (2004) 855.

[11] M.J. Frisch, G.W. Trucks, H.B. Schlegel, G.E. Scuseria, M.A. Robb, J.R. Cheeseman, J.A. Montgomery, Jr., T. Vreven, K.N. Kudin, J.C. Burant, J.M. Millam, S.S. Iyengar, J. Tomasi, V. Barone, B. Mennucci, M. Cossi, G. Scalmani, N. Rega, G.A. Petersson, H. Nakatsuji, M. Hada, M. Ehara, K. Toyota, R. Fukuda, J. Hasegawa, M. Ishida, T. Nakajima, Y. Honda, O. Kitao, H. Nakai, M. Klene, X. Li, J.E. Knox, H.P. Hratchian, J.B. Cross, C. Adamo, J. Jaramillo, R. Gomperts, 
R.E. Stratmann, O. Yazyev, A.J. Austin, R. Cammi, C. Pomelli, J.W. Ochterski, P.Y. Ayala, K. Morokuma, G.A. Voth, P. Salvador, J.J. Dannenberg, V.G. Zakrzewski, S. Dapprich, A.D. Daniels, M.C. Strain, O. Farkas, D.K. Malick, A.D. Rabuck, K. Raghavachari, J.B. Foresman, J.V. Ortiz, Q. Cui, A.G. Baboul, S. Clifford, J. Cioslowski, B.B. Stefanov, G. Liu, A. Liashenko, P. Piskorz, I. Komaromi, R.L. Martin, D.J. Fox, T. Keith, M.A. Al-Laham, C.Y. Peng, A. Nanayakkara, M. Challacombe, P.M.W. Gill, B. Johnson, W. Chen, M.W. Wong, C. Gonzalez, and J.A. Pople, Gaussian 03, Revision B.03, Gaussian, Inc., Pittsburgh PA, 2003.

[12] A. Kahn, J. Chem. Phys. 128 (2008) 075101.

[13] H. Ikeura-Sekiguchi, T. Sekiguchi, Phys. Rev. Lett. 99 (2007) 228102. 